\title{
Exploring the relation between flapping behaviour and accelerometer signal during ascending flight, and a new approach to calibration
}

Article

Accepted Version

Van Walsum, T. A., Perna, A., Bishop, C. M., Murn, C. P., Collins, P. M., Wilson, R. P. and Halsey, L. G. (2020) Exploring the relation between flapping behaviour and accelerometer signal during ascending flight, and a new approach to calibration. Ibis, 162 (1). pp. 13-26. ISSN 0019-1019 doi: https://doi.org/10.1111/ibi.12710 Available at https://centaur.reading.ac.uk/82069/

It is advisable to refer to the publisher's version if you intend to cite from the work. See Guidance on citing.

To link to this article DOI: http://dx.doi.org/10.1111/ibi.12710

Publisher: Wiley

All outputs in CentAUR are protected by Intellectual Property Rights law, including copyright law. Copyright and IPR is retained by the creators or other copyright holders. Terms and conditions for use of this material are defined in the End User Agreement. 


\section{www.reading.ac.uk/centaur}

\section{CentAUR}

Central Archive at the University of Reading

Reading's research outputs online 
MISS TESSA ABIGAIL VAN WALSUM (Orcid ID : 0000-0002-9151-6314)

DR. CAMPBELL P. MURN (Orcid ID : 0000-0003-4064-6060)

Article type : Original Paper

Editor: Auriel Fournier

Running head: Accelerometry and flight in the Harris's Hawk

\title{
Exploring the relation between flapping behaviour and accelerometer signal during ascending flight, and a new approach to calibration
}

\author{
TESSA A. VAN WALSUM ${ }^{1 *}$, ANDREA PERNA ${ }^{1}$, CHARLES M. BISHOP ${ }^{2}$, CAMPBELL P. $^{2}$ \\ MURN $^{3}$, PHILIP M. COLLINS ${ }^{1}$, RORY P. WILSON ${ }^{4}$, LEWIS G. HALSEY $^{1}$ \\ ${ }^{1}$ Life Sciences, University of Roehampton, SW15 4JD, London, UK \\ ${ }^{2}$ Life Sciences, University of Bangor, LL57 2DG, Bangor UK \\ ${ }^{3}$ Hawk Conservancy Trust, SP11 8DY, Andover UK \\ ${ }^{4}$ Life Sciences, Swansea University, SA2 8PP, Swansea United Kingdom \\ *Corresponding author. \\ vanwalst@roehampton.ac.uk
}

We understand little about the energetic costs of flight in free-ranging birds; in part since current techniques for estimating flight energetics in the wild are limited. Accelerometry is known to estimate energy expenditure through body movement in terrestrial animals, once calibrated using a treadmill with chamber respirometry. The flight equivalent, a wind tunnel with mask respirometry, is particularly difficult to instigate, and has not been applied to calibrate accelerometry. We take the first steps in exploring a novel method for calibrating accelerometers with flight energy expenditure. We collected accelerometry data for Harris's Hawks Parabuteo unicinctus flying to varying heights up to $4.1 \mathrm{~m}$ over a small horizontal distance; the mechanical energy expended to gain height can be estimated from physical first principles. The relationship This article has been accepted for publication and undergone full peer review but has not been through the copyediting, typesetting, pagination and proofreading process, which may lead to differences between this version and the Version of Record. Please cite this article as doi: 10.1111/ibi.12710

This article is protected by copyright. All rights reserved. 
between accelerometry and mechanical energy expenditure was strong, and while a simple wing flapping model confirmed that accelerometry is sensitive to both changes in wing beat amplitude and frequency, the relationship was explained predominately by changes in wing beat frequency, and less so by changes in amplitude. Our study provides initial, positive evidence that accelerometry can be calibrated with body power using climbing flights, potentially providing a basis for estimating flapping flight metabolic rate at least in situations of altitude gain.

Keywords: Harris Hawk, dynamic body acceleration, energetics, wing beat frequency, wing beat amplitude

Volant birds can travel further and faster than animals employing other modes of locomotion. The ability to fly underpins much of avian foraging and migratory behaviour, yet powered flight is considered to require considerable energy expenditure (Schmidt-Nielsen 1972, Nudds and Bryant 2000, Piersma 2011). Quantifying those costs is therefore essential to our understanding of bird biology. Presently, however, we know very little about the true costs of flapping flight in unrestrained birds in the wild (Elliott 2016, Hicks et al. 2017), particularly beyond cases of steady-state flight (Pennycuick 2008).

While wind tunnel experiments have proved invaluable for interrogating various aspects of flight biology (Engel et al. 2010), training birds to maintain stationary flight in a current of air (Ward et al. 2002, Sapir and Dudley 2012) is difficult (Welch 2011), and habituating them to wearing a respirometry mask at the same time in order to estimate energy expenditure is an additional problem. Furthermore, the veracity of measurements taken during wind tunnel respirometry has been questioned (Engel et al. 2010). The mask and associated tubing imposes additional weight and drag on the bird, the wind tunnel can elicit boundary effects (Rayner 1994), and captive animals are potentially less physically fit than their wild contemporaries (Schwitzer and Kaumanns 2001). These issues may explain inconsistencies between wind tunnel estimates of flight effort compared to field-based estimates (Liechti and Bruderer 2002). For example, the heart rate of wild geese during flight tends to be low (Bishop et al. 2015) compared to that of geese during wind tunnel experiments (Ward et al. 2002). Furthermore, the tethering effect of the mask limits the bird's freedom of movement, which may also serve to increase its energy costs, and restricts investigation to scenarios of steady state, uni-directional flight. Other approaches for measuring the energetic costs of flight include using energy models in conjunction with high-speed kinematics (Askew and Ellerby 2007), but this is a further example of laboratory measurements, which may yield quite different results to free flying birds in their natural environment. Many ecological and behavioural questions can only be resolved in a natural setting.

This article is protected by copyright. All rights reserved. 
One of the most promising approaches for investigating energy expenditure during flight in wild animals is to attach a small data logger to the subject animal that records a proxy of energy expenditure. Calibrating the proxy with energy expenditure in the laboratory enables quantified estimates of energy expenditure to be calculated from measures of the proxy recorded in the field (Sapir et al. 2010). For example, calibrations between heart rate and energy expenditure obtained for two species of geese (Ward et al. 2002) were applied to heart rate recordings of Bar-headed Geese Anser indicus on migration from Mongolia to India through the Himalayas, estimating energetic savings for these birds from flying close to the ground compared to ascending progressively across the mountain range (Bishop et al. 2015). However, applying such 'biologging' to quantify energy expenditure in birds while flying is in its infancy (Guillemette et al. 2012, Elliott et al. 2013, Elliott et al. 2014, Weimerskirch et al. 2016) with few proxy calibrations available. This is, at least in part, because calibrating energetics proxies for flying birds is very difficult, given the logistics, for example, of wind tunnel respirometry.

Accelerometers are used as biologging devices that record the acceleration of the body of the animal. Both in theory (Gleiss et al. 2011) and in practice (Wilson et al. 2006), recordings from accelerometers attached to a central point on an animal's body relate well to the levels of movement of that animal, and in turn its energy expenditure during periods of activity. A now commonly used derivative of accelerometry data used as a proxy for energy expenditure is termed dynamic body acceleration (DBA) (Halsey et al. 2011, Qasem et al. 2012). During flapping flight, acceleration of the animal's body, and thus DBA, is affected by variation in flapping behaviour (Halsey et al. 2009, Spivey and Bishop 2013, Bishop et al. 2015, Weimerskirch et al. 2016) which is described predominantly by wing beat frequency, wing beat amplitude or a combination of the two (Rayner 1999). Strong relationships between rate of energy expenditure and DBA have been found in a diversity of cursorial birds such as Red Jungefowl (chickens) Gallus gallus, Great Cormorants Phalacrocorax carbo and Macaroni Penguins Eudyptes chrysolophus (Wilson et al. 2006, Green et al. 2009, Halsey et al. 2009). Yet to date there has been no empirical calibration of accelerometry with energy expenditure for birds during flight. The three-dimensional nature of bird flight means that the relationship between DBA and energy expenditure cannot be easily predicted from simple theoretical considerations: birds could switch between different flapping modes as they fly on different slopes, leading to difficult to predict effects on DBA. Our study takes the first steps to address this. We provide the first experimental relationship between accelerometry (as DBA) and rate of energy expenditure (as climb power is associated with the gain in potential energy) in a volant animal, by using variation in climbing slope during free flights to enable climb power to be estimated from physical first principles. These experiments also enabled us to investigate what aspects of wing kinematics (e.g. increased flapping frequency or flapping amplitude) drive

This article is protected by copyright. All rights reserved. 
power output in this particular flight scenario and how effectively DBA can describe these kinematics.

We fitted Harris's Hawks Parabuteo unicinctus with accelerometers and encouraged them to undertake short flapping flights that varied in the height gained between the two falconers. The extra energy (climb power) expended by the bird in achieving these various heights was calculated from physical first principles as the product of the mass of the bird, gravitational acceleration, and the rate of increase in height (Askew et al. 2001, Berg and Biewener 2008). This enabled us to test for and investigate relationships between energy expenditure (as climb power) and DBA in birds without heavy logistical burdens, outside the laboratory, flying freely and without restricting the animals such as obliging them to wear a respirometry mask. We further explored our findings by investigating the relationships between DBA and bird kinematics both empirically and using simple wing flapping models based on sinusoidal waves (Spivey and Bishop 2013); the modelling helps to clarify some common misunderstandings about how cyclical body movement impacts measures of body acceleration.

\section{Methods}

Experimental set-up

We collected data from five (one male and four female) Harris's Hawks weighing between 0.84 - $1.03 \mathrm{~kg}$, at the Hawk Conservancy Trust (HCT) in Andover (UK). Data were collected in the summer and autumn of 2016, under approval of the ethics committee of the University of Roehampton.

We encouraged the hawks to fly to six different heights (range: $0-4.1 \mathrm{~m}$, Figure 1 and Table 1) while covering only a small horizontal distance $(4.1 \mathrm{~m})$. Lured by morsels of chicken (weighing $1-2 \mathrm{~g}$ ), the birds flew back and forth from a falconer on the ground to a falconer standing at different heights on flights of steps up to a balcony. Their body mass therefore increased slightly with each flight; we accounted for this in our analyses by assuming that each piece of food weighed $1.5 \mathrm{~g}$. Each height condition was randomised, and repeated approximately three times per bird. Wind speed was measured with an anemometer and never exceeded $0.3 \mathrm{~m} / \mathrm{s}$ so we considered wind to be negligible for our experiment.

We placed a small accelerometer (9.3 g, 1\% of body mass; GCDC USB accelerometer X16-4) on the lower section of the Harris's Hawk's back, towards the rump where it would not interfere with wing movement (Figure 2). The accelerometer was set to record at $50 \mathrm{~Hz}$ (around 10-fold the wing beat frequency of Harris's hawks). Similar to some previous studies of bird flight

This article is protected by copyright. All rights reserved. 
power and kinematics ( Pennycuick et al. 1989, Askew et al. 2001, Berg and Biewener 2008), flight durations were short, averaging $1.7 \mathrm{~s}$ ( \pm one sd: 0.3 ).

\section{Video recordings}

We video recorded the flight of the birds with a Nikon Coolpix AW110 camera, hand-held by a researcher standing on the ground, perpendicular to the bird's trajectory. The video was used subsequently to check flight durations and times, synchronise the flight times with the accelerometry data, and note any aberrant behaviours by the birds during the flights (e.g. bird not flying to the target); those flights ( $\mathrm{n}=6$ from three birds) were removed prior to analysis. We used the programme IGOR Pro (Wavemetrics Inc., Portland, OR, USA, 2000, version 6.3.5) with the Ethographer package (Sakamoto et al. 2009) in concert with the video footage, to extract the acceleration traces representing each flight.

\section{Estimating climb power}

From the height gained by a hawk during each flight (Table 1), along with the duration of the flight and the mass of the bird, mean climb power during the flight can be calculated by:

$$
\text { Climb power }\left(\mathrm{Js}^{-1}\right)=\frac{\text { mass }(\mathrm{kg}) \times \text { gravitational acceleration }\left(9.81 \mathrm{~ms}^{-2}\right) \times \text { height gained }(\mathrm{m})}{\text { flight duration }(\mathrm{s})}
$$

This article is protected by copyright. All rights reserved. 
Table 1. Height gain and flight distance represented by each experimental condition. Average height varied slightly within each condition due to slight variations in the stance adopted by the two falconers.

\begin{tabular}{|c|c|c|c|c|}
\hline $\begin{array}{c}\text { Flight } \\
\text { condition }\end{array}$ & $\begin{array}{c}\text { Mean height gain } \\
\text { (and range) (m) }\end{array}$ & $\begin{array}{c}\text { Mean flight } \\
\text { distance (and } \\
\text { range) (m) }\end{array}$ & $\begin{array}{c}\text { Mean flight duration } \\
\text { and range (s) }\end{array}$ & $\begin{array}{c}\text { \# Birds (and } \\
\text { \# flights) }\end{array}$ \\
\hline H1 & 0 & 4.1 & $1.6(1.2-2.2)$ & $5(14)$ \\
\hline H2 & $1.3(1.2-1.6)$ & $4.3(4.3-4.4)$ & $1.6(1.2-2.4)$ & $5(17)$ \\
\hline H3 & $1.8(1.6-2.0)$ & $4.5(4.4-4.6)$ & $1.6(1.3-2.6)$ & $5(19)$ \\
\hline H4 & $2.5(2.3-2.9)$ & $4.8(4.7-5.0)$ & $1.7(1.3-2.2)$ & $4(13)$ \\
\hline H5 & $3.8(3.5-4.2)$ & $5.6(5.4-5.9)$ & $1.9(1.5-2.5)$ & $4(12)$ \\
\hline H6 & $4.1(3.9-4.3)$ & $5.8(5.7-5.9)$ & $2.1(1.7-2.5)$ & $5(13)$ \\
\hline
\end{tabular}

\section{Accelerometry data analysis}

Accelerometers measure both dynamic (body movement) and static acceleration (gravity) (Gleiss et al. 2011), and the tag model we used recorded acceleration along three orthogonal axes (heave, surge and sway) measured in absolute $g\left(1 g=9.81 \mathrm{~m} \mathrm{~s}^{-2}\right)$. Thus, the acceleration of the bird's body due to the movement of its wings could be determined by recording the acceleration experienced by the data logger attached to a fixed point on the body, such as the lower back, and then from those data by extracting an approximation of absolute $g$ due only to dynamic acceleration (Gleiss et al. 2011, Halsey et al. 2011). This extraction was achieved in our study by removing an approximation of the static acceleration calculated as the mean of each accelerometry axis over the duration of the flight, similar to employing a running mean (Shepard et al. 2008). Preliminary analysis showed that we found a stable DBA within the average flight duration of the hawk. The resulting absolute dynamic values were then summed to produce the derivation termed 'overall dynamic body acceleration', hereafter, DBA.

This article is protected by copyright. All rights reserved. 


\section{Calculating flapping kinematics from the accelerometry data}

All the flapping analyses were implemented in Matlab v.7.9.0.529. We projected the accelerometer signal along one dimension. This dimension was defined as the major flapping axis of the Harris's Hawk, determined independently for each flight through principal component analysis of the three-dimensional accelerometer recordings. Next, we applied a cubic spline interpolation of this accelerometer signal with a temporal resolution of 250 fixes per second ( 5 times the original resolution of the data). This step was included because the temporal resolution for detecting wing beat frequency is limited by the temporal discretisation of the data, however the accelerometer signal itself carries sufficient information for a much more accurate estimation, because the signal is repeated over multiple flapping cycles. This information was integrated in the subsequent steps of analysis.

We estimated wing beat frequency by computing a temporal autocorrelation of the interpolated accelerometer signal and by detecting the time lag that corresponded to the second highest peak in the autocorrelation function (the first highest peak is the trivial autocorrelation maximum at zero delay). This time lag gave the time period $T$ of one flapping cycle, the wing beat frequency being $1 / T$. In four flights of one bird, the second highest peak in the autocorrelation function was of similar height to the third highest peak and its position indicated incorrect values of wing beat frequency (higher than $8 \mathrm{~Hz}$ or lower than $4 \mathrm{~Hz}$, clearly different from what we could observe in the video footage). For these four flights, we manually forced selection of the third highest peak.

Acceleration amplitude along the major flapping axis is a measure of the amplitude of acceleration of the bird's body (Usherwood et al. 2011, Spivey and Bishop 2013), which in turn is assumed to result predominantly from wing flapping. Acceleration amplitude was estimated directly from the local maxima and local minima of the interpolated accelerometer signal. As the accelerometer signal had multiple local maxima and minima, some of which were determined by noise (or by higher harmonics of wing movements), we limited the analysis to local maxima and minima that were also global maxima or minima within a time window of $70 \%$ of one flapping cycle. As an aggregate measure of amplitude of acceleration during the flap cycles over the entire flight, we kept the value that corresponded to the 80th percentile of the absolute amplitude of local maxima and minima, under the assumption that this would be only minimally sensitive to extreme variations of amplitude associated with take-off and landing. Acceleration amplitude was used to estimate the movement amplitude of the bird's body (hereafter termed 'body movement amplitude', $\mathrm{cm}$ ) by considering the body to fluctuate over time following a pure sine wave (Spivey and Bishop 2013). Body movement amplitude is assumed to be proportional to wing beat amplitude and thus an indirect measure of it (Hedrick et al. 2004, Usherwood et al. 2011, Taylor et al. 2017) (supplementary material includes a Matlab code to calculate the wing

This article is protected by copyright. All rights reserved. 
beat amplitude and body movement amplitude).

From the measured values of DBA we calculated an estimated measure of 'body power', or the power produced by flapping. Under relatively well supported assumptions of sinusoidal flapping, body power is proportional to the amplitude of the accelerometer signal and inversely proportional to the squared wing-beat frequency (see for instance Spivey and Bishop 2013), so here we defined body power simply as body power $=\frac{D B A^{2}}{W B F}$ (this is analogous to other definitions of body power based on RMS (Root Mean Square) contrast of accelerometer signal: RMS contrast and DBA are both proportional to the amplitude of the sinusoidal flapping signal, body power $\left.=\frac{R M S^{2}}{W B F}\right)$

\section{Statistical analyses}

Statistical analyses focussed on general linear models implemented in the programming environment R 3.4.0 (Team 2013), using the lme4 package. In different models, DBA ( $g$ ), climb power $\left(J s^{-1}\right)$ and climb energy per wingbeat $(J)$ were the outcome variables, with either body movement amplitude $(\mathrm{cm})$, wing beat frequency $(\mathrm{Hz})$, climb power or body power $\left(\mathrm{JS}^{-1}\right)$ as single predictor variables. All models included bird ID as a random factor, allowing slope intercept and gradient to differ for each bird. We then performed a cross-validation analysis to quantify the predictive validity of our model calibrating DBA with climb power. Using a jack knife approach, we simulated the scenario of estimating climb power from measures of DBA obtained from a new individual. We excluded one bird from the dataset in generating the relationship between climb power and DBA, and then used that relationship to compare climb power against DBA-predicted climb power, for 10 randomly selected values of DBA. Mean absolute and mean algebraic percentage error was calculated for these 10 samples. This process was repeated for all five birds and overall means were then calculated.

$\mathrm{R}^{2}$ values for mixed effects models were calculated following the method of Nakagawa and Schielzeth (2013) using the MuMIn package. Because the $p$ value is typically highly imprecise, here we consider it to be only a tentative indication of the strength of evidence for observed patterns in the data ( Fisher 1959, Boos and Stefanski 2011, Halsey et al. 2015). To enhance interpretation of the $p$ value, we have supplemented reporting the $p$ values with further information following the three key recommendations of the American Statistical Association (Wasserstein and Lazar 2016), further explained in Altman and Krzywinski (2017), which enable assessment of the strength of evidence for the falsehood of the null hypothesis. First, we provided estimates of the false discovery rates associated with each null hypothesis - the

This article is protected by copyright. All rights reserved. 
expected proportion of the rejected null hypotheses that are false rejections. These were calculated based on predicted statistical power of $80 \%$ and the heuristic for low-throughput testing recommended by Altman and Krzywinski (2017) to predict the proportion of tests that are truly null: $50 \%$ for primary research questions and $75 \%$ for secondary research questions. Second, we calculated the upper bound for the Bayes factor ( Sellke et al. 2001, Boos and Stefanski 2011) - the largest possible Bayes factor over any (reasonable) choice of the prior distribution for the alternative hypothesis. The value represents the ratio of average likelihoods under the alternative and null hypotheses, i.e. a quantification of the extent to which the alternative hypothesis (that the effect size is not null, i.e. not 0), is more likely. Third, all our data figures include 95\% confidence intervals, both standard and bootstrapped (Loftus 1993, Lavine 2014).

\section{Results}

\section{Empirical data analysis}

Five Harris's Hawks undertook a total of 88 flights that were included in the analyses. Cleveland plots indicated no clear outliers in the data set. The observations:covariates ratio was never lower than 24 for the models constructed, which is acceptable (Zuur et al. 2013). There was no relationship between the Pearson residuals and the fitted values from this study's main model: DBA climb power + [bird_ID]. None of the Cook's distances were outliers. The relationship between observed data and fitted data for this model was approximately unitary. Plots of Pearson residuals against each model covariate in this study's analyses did not indicate any obvious non-linearity (48).

To generate relationships between rate of energy expenditure and DBA, we plotted mean DBA against estimated climb power (Figure 3); the plot indicated that they correlate positively. The

$\mathrm{R}^{2}$ values for climb power regressed against DBA for each bird separately ranged between 0.58 and 0.80. A linear mixed model to predict DBA from climb power, including bird identity as a random factor, indicated a strong relationship (Table 2). To quantify the predictive accuracy of the relationship between climb power and DBA, we performed a cross-validation analysis. Overall mean absolute error was $19.22 \pm 1.16 \%$ (range of mean absolute error: $0.22-68.08 \%$ ), while overall mean algebraic error was $-4.00 \pm 1.96 \%$ (range of mean algebraic error: $-68.08-$ $42.41 \%)$.

Consequently, we then explored the relationships between key aspects of wing kinematics and climb power, and how effectively DBA described those wing kinematics (Table 2). The flight kinematic variables we investigated at this point were body movement amplitude (a proxy for

This article is protected by copyright. All rights reserved. 
wing beat amplitude) and wing beat frequency. DBA was related statistically significantly but not strongly to body movement amplitude (Figure 4A), and related more strongly to wing beat frequency (Figure 4B). Similarly, climbing power was related statistically significantly but not strongly to body movement amplitude (Figure 4C), and more strongly to wing beat frequency (Figure 4D). Consequently, there was a fairly strong positive relationship between climb energy per wing beat and climb power (Figure 4E). Finally, climb power was regressed against $\frac{D B A^{2}}{W B F}$, which is the theoretical relationship derived by Spivey and Bishop (2013) for body power perceived by the body-mounted accelerometer (Figure 4F), but the relationship had a weaker correlation (marginal $\mathrm{R}^{2}$ ) than that for DBA, or even wing beat frequency, alone.

Table 2. Model outputs, accounting for repeated measures within each bird, investigating the relationships between dynamic body acceleration (DBA, $g$ ), climb power $\left(J s^{-1}\right)$, wing beat frequency (WBF; Hz), body movement amplitude (BMA; $\mathrm{cm}$ ), climb energy per wingbeat (Energy per wingbeat; $J$ ) and body power $\left(J S^{-1}\right)$. Marginal $R^{2}$ describes the proportion of variance explained by the fixed factor(s) alone; Conditional $R^{2}$ describes the proportion of variance explained by both the fixed factor(s) and the random factor (bird ID). eFDR = estimated false discovery rate. The Bayes factor bound calculates the upper bound of the Bayes factor based on the reported $P$ value, and indicates the ratio of the likelihood that the alternative hypothesis is true against the likelihood that the null hypothesis is true. See the main text for further details.

\begin{tabular}{|c|c|c|c|c|c|c|c|}
\hline $\begin{array}{l}\text { Associated } \\
\text { Figure }\end{array}$ & Model & Slope $( \pm$ se $)$ & Marginal $R^{2}$ & Conditional $R^{2}$ & $P$ value & $\begin{array}{c}\text { eFDR } \\
(\%)\end{array}$ & $\begin{array}{c}\text { Bayes factor } \\
\text { bound }\end{array}$ \\
\hline Figure 3 & $\begin{array}{l}\text { DBA } \sim \text { climb } \\
\text { power }\end{array}$ & $0.092 \pm 0.009$ & 0.54 & 0.64 & $<0.001$ & 0.12 & 53 \\
\hline Figure 4A & $\mathrm{DBA} \sim \mathrm{BMA}$ & $0.28 \pm 0.067$ & 0.17 & 0.17 & $<0.001$ & 0.37 & 53 \\
\hline Figure 4B & $\mathrm{DBA} \sim \mathrm{WBF}$ & $1.88 \pm 0.27$ & 0.38 & 0.52 & $<0.001$ & 0.37 & 53 \\
\hline Figure 4C & $\begin{array}{c}\text { Climb power } ~ \\
\text { BMA } \\
\end{array}$ & $1.46 \pm 0.651$ & 0.06 & 0.19 & 0.02 & 6.98 & 5 \\
\hline Figure 4D & $\begin{array}{c}\text { Climb power } ~ \\
\text { WBF }\end{array}$ & $17.8 \pm 2.0$ & 0.48 & 0.64 & $<0.001$ & 0.37 & 53 \\
\hline Figure 4E & $\begin{array}{l}\text { Energy per } \\
\text { wingbeat } ~ \\
\text { climb power }\end{array}$ & $0.173 \pm 0.012$ & 0.61 & 0.84 & $<0.001$ & 0.37 & 53 \\
\hline Figure $4 \mathrm{~F}$ & $\begin{array}{c}\text { Power } \sim \\
\text { climb power }\end{array}$ & $6.71 \pm 0.727$ & 0.32 & 0.62 & $<0.001$ & 0.37 & 53 \\
\hline
\end{tabular}

This article is protected by copyright. All rights reserved. 


\section{Modelled data analysis}

Superficially, one might conclude that changes in wing beat frequency will not be recognised by changes in DBA (or related measures such as RMS) because DBA depends only on the amplitude of the acceleration profile and not its frequency (Fig. 5). The total DBA of a flapping cycle corresponded to the area shaded in grey in Figure 5a. If the bird produced an identical accelerometer profile, but flapped at double the frequency (Fig.5b), the total DBA of a flap cycle would now be reduced to one half the original, but there would now be two identical flapping cycles per unit of time, so that average DBA calculated across multiple flap cycles would be identical (see the appendix for a proof).

However, it would be wrong to conclude that the profile presented in Figure $5 \mathrm{~b}$ would result from the bird increasing its wing beat frequency while maintaining constant wing beat amplitude. There is a crucial and fundamental distinction to be made between the amplitude of the signal in the recorded acceleration trace $(\mathrm{g})$ and the amplitude of the bird's wing flaps $(\mathrm{cm})$. The amplitude of the accelerometer profile carries information about both the amplitude and the frequency at which the bird flaps its wings. A larger flapping amplitude for a given wing beat frequency registers higher acceleration values and, for a given flapping amplitude, a higher wing beat frequency will register higher acceleration values. Simply put, a flapping wing must speed up and slow down more rapidly if it is moving further per unit time, or flapping more frequently. Thus, even if inspection of the profile of the bird's body movements in $\mathrm{cm}$ (in reaction to its wing beats) does not show any change in gain in response to a change in its wing beat frequency (Figure 6a), DBA derived from an accelerometer instrumented to the bird's back should nonetheless recognise this variation in flapping behaviour (Figure 6b).

\section{Discussion}

During flapping flight, to gain height birds must expend energy. We took advantage of this fact to generate relationships between the output of an accelerometer and the rate of mechanical energy expenditure of volant birds by instrumenting the accelerometer to the back of Harris's Hawks while they undertook ascending flights.

\section{The relationship between climb power, DBA and wing kinematics}

Although our experimental design induced the birds to ascend to different heights and thus expend different total amounts of energy, this did not ensure that they would vary their mean climb power. Fortunately, however, climb power did vary, providing variation that might covary with DBA. DBA derived from the recorded accelerometry data during these flights related to 
climb power positively and strongly (Figure 3), characterised by an overall mean absolute prediction error of less than 20\%, and overall mean algebraic error (giving an indication of the predictive error if mean climb power across multiple birds was estimated) of $-4 \%$. This augurs well for the future use of accelerometers to estimate energy expenditure in volant birds.

Variation in DBA (due to variation in climb power) was explained more by changes in wing beat frequency (Fig. 4b) than by changes in wing beat amplitude (measured in terms of body movement amplitude; Figure 4a). The birds' increase in wing beat frequency to increase power was clear (Fig. 4d) despite the variation in wing beat frequency being small (across all birds typically ranging from about 4.7 to about $5.8 \mathrm{~Hz}$ ). Our wing flap models demonstrated that DBA can be sensitive to both changes in body movement amplitude and wing beat frequency (Fig. 6); it appears that the Harris's Hawks enacted relatively small changes in wing beat frequency in order to generate relatively large changes in climb power. This has been quantified once before, in Bar-headed Geese (Bishop et al. 2015). Small increases in wing beat frequency might be expected to associate with relatively high power costs given that, for horizontal steady flight, power requirement should be proportional to wing beat frequency cubed (Lilienthal 2001). However, the wing beat frequency of the Harris's Hawks leaves quite a lot of variation in DBA and climb power unexplained, and a regression of climb energy expended per wing beat against climb power, while strong, includes a fair amount of variability (Figure 4E). Our wing flap models indicated that DBA is likely to be somewhat sensitive to changes in wing beat frequency, leaving the possibility that the birds made other changes to their flight kinematics over and above wing beat frequency and wing beat amplitude to change their climb power. Similarly, Frigatebirds Fregata spp. hold wing beat frequency fairly constant yet heart rate per wing beat (a proxy of power output per wing beat) varies substantially during the course of a flight (Weimerskirch et al. 2016). In both these cases, one possibility is that the birds change stroke plane angle, as has been reported in pigeons during short, height-gaining flights where power output per wing beat was higher when the required flight angle (and hence predicted power) was greater (Berg and Biewener 2008).

The calculated mean maximum climb power exhibited by the Harris's Hawks during flights in the present study was about $25 \mathrm{JS}^{-1}$, which is similar to that reported for $2 \mathrm{~s}$ climbing flights by the same species in an earlier study (Pennycuick et al. 1989; their Figure 7). This is, of course, only a part of the total power costs of flight for the bird, which include muscle contractions of the wings and other body parts, the costs to overcome drag and basic lift, and basal metabolic rate. For example, during flight a bird's basal metabolic rate could constitute 4 to $10 \%$ of its total metabolic costs (Nudds and Bryant 2000, Piersma 2011), and flight muscle efficiency is typically less than $20 \%$ (Rayner 1999). In reality, total power during a flight is likely to be many times higher than calculated climb power, and could vary with mechanical power (Rayner 1999,

This article is protected by copyright. All rights reserved. 
Pennycuick 2008, Engel et al. 2010). The gross energy costs for a human to jump horizontally is around 8-fold greater than the energy expenditure calculated from physical first principles (Halsey et al. 2016). Similarly, the gross energy costs to ascend and descend a ladder are around 13-fold greater (Halsey et al. 2016). Nudds and Bryant (2000) reported strong inter-specific correlations between gross power output and body mass during flight in birds based on a literature review of empirical studies. For short flights, their relationship predicted gross power to be $250 \mathrm{~J} \mathrm{~s}^{-1}$ for a $1 \mathrm{~kg}$ bird, which is about 10 times the maximum mean climb power exhibited by the hawks in the current study. It should be borne in mind that shorter flights are particularly energetically demanding, due to take-off costs (Nudds and Bryant 2000) and the higher power costs associated with slower flight speeds (Engel et al. 2010). Relationships between DBA and climb power could be a valuable platform for estimating flight metabolic rate as our understanding of a bird's internal power costs becomes clearer, and even without estimates of internal power costs, such relationships should reflect relative changes in energy expenditure.

The precise mathematical relationship between amplitude of body movement and accelerometer signal can be derived as follows. Consider the case of a bird which has flapping described by a pure sine wave, such that the $z$ position of its body (to which the accelerometer is attached) fluctuates over time from a minimum height $-B$ to a maximum height $+B$, with period $T$. In this case we have

$z(t)=B \sin (\omega t)$ where we used $\omega=\frac{2 \pi}{T}$ to represent the angular velocity and simplify the notation. The accelerometer does not directly record the bird's body position at any given time $t$, $z(t)$, but simply its acceleration, that is, the second derivative of body position. Indicating this acceleration with a capital $Z(t)$ we have:

$$
Z(t)=\frac{d^{2} z}{d t^{2}}=B \omega^{2} \sin (\omega t)
$$

Importantly, the accelerometer profile describes a sine wave, with the same period or frequency as the body (the $\sin (\omega t)$ part is identical in the two equations), but where the amplitude has now changed from $B$ (a function of body movement amplitude only) to $B \omega^{2}$ (a function of both body movement amplitude and wing beat frequency).

Under these assumptions, we can directly calculate the amplitude of body movements $(\mathrm{cm})$ from the amplitude and frequency of flapping recorded by the accelerometer. For example, in our data we have typical values of accelerometer amplitude $A \approx 5 \mathrm{~g}$, or $A=5 \times 9.81 \mathrm{~ms}^{-2}$, and $T \approx 0.2 \mathrm{~s}$, from which $\omega=2 \times \pi / 0.2 \mathrm{~s}^{-1}$ and $B=A / \omega^{2}=5 \times 9.81 /(2 \times \pi / 0.2)^{2} \mathrm{~m}=0.05 \mathrm{~m}=5 \mathrm{~cm}$. (See

This article is protected by copyright. All rights reserved. 
also Spivey and Bishop 2013 for a more accurate and complete analysis of the sinusoidal model).

Real birds are unlikely to flap with a perfect sinusoidal profile. However, as long as the flapping profile is periodic, it can be described as the sum of multiple sine functions by Fourier series approximation and the same mathematical reasoning above holds independently for each of the harmonics.

\section{Improving the DBA-power relationships}

Our experiments included sources of potential error that could increase noise in the relationships reported. Defining and discerning the start and end of each flight is an imperfect endeavour, resulting in some degree of inconsistency and inaccuracy in measuring flight duration and selecting the associated accelerometry trace. The exact height gained by a bird was also subject to error due to variation within each height condition of the exact body postures and hand placements of the falconers, though most of this variation was accounted for by inspecting the video footage. Because of the short duration of the flights, variation in how take-off and landing was incorporated into calculations for each flight could instigate considerable noise to the reported relationships. We investigated whether removing the start and end of the accelerometry trace for each flight improved the relationship specifically between DBA and climb power. We progressively shortened the analysed flights by $0.1 \mathrm{~s}$ intervals at both ends simultaneously (up to $0.3 \mathrm{~s}$ at each end), and found that this tended to slightly weaken the relationship. This process therefore provided no evidence that our assessment of the flight start- and end-points were inaccurate. If the birds could be trained to undertake flights incorporating greater height gain while maintaining the short horizontal flight distance, this might serve to improve the DBApower relationship, unless for extended flights of this type the birds choose to maintain a more consistent power output between height conditions. We were able to position the logger on the back at a consistent point within and between individual birds, which is important to reduce noise-based variation in the relationships between climb power, DBA and flight kinematics between birds. The results of the present study have confirmed that DBA depends partly on body movement amplitude (Sapir et al. 2010, Bishop et al. 2015), which in turn will depend on logger positioning since differing locations may influence the degree of oscillation experienced by the logger. Thus, it is possible that certain logger positions return stronger predictive relationships between climb power and DBA or body movement amplitude than others (Halsey et al. 2008).

This article is protected by copyright. All rights reserved. 
Our data indicate considerable variation in the relationship between DBA and climb power among individuals (Figure 3). Such variation in energy-proxy relationships among individuals is typical e.g. (Halsey and White 2010, Green 2011, Halsey et al. 2011), and is ripe for investigation with detailed kinematic data. Inter-individual variability can be recognised statistically in the errors associated with estimates of energy expenditure at the group level (Green et al. 2003, Green 2011, Lyons et al. 2013), where mean values for the group tend to be accurate (e.g. Halsey et al. 2007).

\section{The future for accelerometry to investigate flight energetics}

We need ways to estimate energy expenditure in free-flying birds, and other volant animals, at a high resolution, and non-invasive instrumentation of data loggers is currently the most tractable option (though surgical implants may be preferential for long term deployments (White et al. 2013)). Researchers have only just begun to apply accelerometry measurements to estimate the energy expenditure of flapping flight. Bishop et al. 2015 showed that in Bar-headed Geese migrating through the Himalayas, variations in heart rate and accelerometry closely track each other (their Figure 1); given that heart rate correlates with rate of oxygen consumption in this species (Groscolas et al. 2000), we can reasonably conclude that accelerometry can predict the power costs of flapping flight, at least in geese. Heart rate also correlates with accelerometry metrics in airborne Griffon Vultures Gyps fulvus (Duriez et al. 2014), while Hicks et al. (2017) demonstrated that accelerometry relates to power output in European Shags Phalacrocorax aristotelis. The current study supports these conclusions, this time providing direct evidence of a relationship between DBA and mechanical power, the latter derived from first principle calculations. Further work is required to produce calibrations for application in the field. In situations where birds undertake extended periods of ascending flapping flight e.g. (Clarke et al. 2007, Bishop et al. 2015), which may have an important effect on their energy stores or fatigue, the approach presented in the current study can be particularly valuable.

\section{Acknowledgements}

We are grateful to staff at the Hawk Conservancy Trust, in particular those staff at the Trust who supported the experiments. We would like to thank the reviewers who gave overall positive and informative feedback.

This article is protected by copyright. All rights reserved. 
Ethical statement

All research undertaken has been approval by the ethics committee of the University of Roehampton (Reference LSC 17/209).

\section{Funding statement}

Through the University of Roehampton, a Santander/Ede \& Ravenscroft young researcher small grant was awarded to TvW.

\section{Data accessibility}

The datasets supporting this article, as well as a Matlab code for running our wingbeat analysis (as described in our methods section) have been uploaded to Figshare.com.

\section{Competing interests}

We have no competing interests.

\section{Author contributions}

Data collection, analysis, interpretation of data, first draft, review (TvW, AP, LH). Data collection, analysis, interpretation of data, review (PC, CB). Interpretation of data, review (RW, CM). All authors have approved final version of the manuscript and have agreed to be accountable for all aspects of the work in ensuring that questions related to the accuracy or integrity of any part of the work are appropriately investigated and resolved.

\section{Figure Legends}

Figure 1 Schematic diagram of the experimental setup. $(\mathrm{H} 1=0 \mathrm{~m}$ height gain; $\mathrm{H} 6=4.5 \mathrm{~m}$ height gain; see main text for further details). For each height condition the bird flew from falconer 1 to falconer 2 .

Figure 2 Attachment (left) and location (right) of the accelerometer, placed on the back of the Harris's Hawk using surgical tape. The accelerometer was protected from rain and dust by a thin plastic film.

Figure 3. Regressions of mean dynamic body acceleration (DBA) against mean climb power during short flights by Harris's Hawks $(N=5)$. The plotted data represent single values $(n=88)$, colour- and shape-coded to identify each bird. Colour- and style-coded lines of best fit are shown; NB that one best fit line (green, long dash) substantially obscures another (olive, short dash). Bird 1, red full and circle symbols, $R^{2}=0.80$, Bird 2, olive short dash and triangle 
symbols, $R^{2}=0.58$, Bird 3, green long dash and squared symbols, $R^{2}=0.64$, Bird 4, blue wide dash and plus symbols, $R^{2}=0.70$, Bird 5 , mauve stippled and cross squared symbols, $R^{2}=0.66$.

Figure 4. Relationships between flight kinematics, dynamic body acceleration (DBA) and estimates of climb power during short flights by five Harris's Hawks $(n=88)$. In each panel, the black line represents the line of best fit returned from a linear mixed model that included bird identity as a random factor. The grey dashed lines indicate the $95 \%$ confidence interval around the line of best fit derived from standard calculations, while the grey stippled lines indicate the $95 \%$ confidence intervals derived from a bootstrap procedure based on 200 iterations.

Figure 5. The average dynamic body acceleration (DBA) per unit time only depends on the amplitude of the accelerometer signal and not on its frequency. (a) Idealised flapping profile recorded by the accelerometer. The average DBA of a flapping cycle corresponds to the area of the shaded region, divided by the length of the flapping cycle (in this example $0.2 \mathrm{~s}$ ). (b) Accelerometer profile identical to the one in (a), but with double the frequency. The shaded area in each cycle is now only half the area in (a), but there are now twice as many cycles per unit time, so that the average DBA is unchanged.

Figure 6. Modelled relationships between body movement, acceleration amplitude and wing beat frequency. (a) Two hypothetical flapping profiles, here exemplified by sinusoidal curves, having exactly the same amplitude (in $\mathrm{cm}$ of body oscillations) but different frequencies (black curve: $5.5 \mathrm{~Hz}$; red dashed curve: $4.125 \mathrm{~Hz}$ ). The body movements exemplified in (a) produce acceleration profiles (in units of $g$ ) with identical frequencies (b), but the amplitude has changed - faster body movements produce higher acceleration amplitudes for the same body movement amplitudes.

\section{References}

Altman, N. and Krzywinski, M. (2017). Points of significance: interpreting P values.

Askew, G. N., Marsh, R. L. and Ellington, C. P. (2001). The mechanical power output of the flight muscles of blue-breasted quail (Coturnix chinensis) during take-off. J. Exp. Biol. 204, 3601-3619.

Askew, G. N. and Ellerby, D. J. (2007). The mechanical power requirements of avian flight. Biology Letters 3, 445-448.

Berg, A. M. and Biewener, A. A. (2008). Kinematics and power requirements of ascending and descending flight in the pigeon (Columba livia). J. Exp. Biol. 211, 1120-1130.

This article is protected by copyright. All rights reserved. 
Bishop, C. M., Spivey, R. J., Hawkes, L. A., Batbayar, N., Chua, B., Frappell, F. B.,

Milsom, W. K., Natsagdorj, T., Newman, S. H. and Scott, G. R. (2015). The roller coaster

flight strategy of bar-headed geese conserves energy during Himalayan migrations. Science 347, 250-254.

Boos, D. D. and Stefanski, L. A. (2011). P-value precision and reproducibility. The Am. Stat. 65, 213-221.

Clarke, J. A., Ksepka, D. T., Stucchi, M., Urbina, M., Giannini, N., Bertelli, S., Narvaez, Y. and Boyd, C. A. (2007). Paleogene equatorial penguins challenge the proposed relationship between biogeography, diversity, and Cenozoic climate change. Proc. Natl. Acad. Sci. U. S. A. 104, $11545-11550$.

Duriez, O., Kato, A., Tromp, C., Dell'Omo, G., Vyssotski, A. L., Sarrazin, F. and RopertCoudert, Y. (2014). How cheap is soaring flight in raptors? A preliminary investigation in freely-flying vultures. PLoS One 9, e84887.

Elliott, K. H. (2016). Measurement of flying and diving metabolic rate in wild animals: Review and recommendations. Comp. Biochem. and Phys. Part A: Mol. \& Int. Phys.

Elliott, K. H., Chivers, L. S., Bessey, L., Gaston, A. J., Hatch, S. A., Kato, A., Osborne, O., Ropert-Coudert, Y., Speakman, J. R. and Hare, J. F. (2014). Windscapes shape seabird instantaneous energy costs but adult behavior buffers impact on offspring. Move. Eco. 2, 17. Elliott, K. H., Ricklefs, R. E., Gaston, A. J., Hatch, S. A., Speakman, J. R. and Davoren, G. K. (2013). High flight costs, but low dive costs, in auks support the biomechanical hypothesis for flightlessness in penguins. PNAS.

Engel, S. and Bowlin, M.S., Hedenstrom, A. (2010). The role of wind-tunnel studies in integrative research on migration biology. Int. and Comp. Bio. 50, 323-335.

Fisher, R. A. (1959). Statistical methods and scientific inference.

Gleiss, A. C., Wilson, R. P. and Shepard, E. L. C. (2011). Making overall dynamic body acceleration work: on the theory of acceleration as a proxy for energy expenditure. Meth. in Eco. and Evo. 2, 23-33.

Green, J., Halsey, L., Wilson, R. P. and Frappell, P. B. (2009). Estimating energy expenditure This article is protected by copyright. All rights reserved. 
of animals using the accelerometry technique: activity, inactivity and comparison with the heartrate technique. Green J., Halsey L.G., Wilson R.P., Frappell P.B. J. Exp. Biol. 212, 471-482.

Green, J. A. (2011). The heart rate method for estimating metabolic rate: review and recommendations. Comp. Biochem. and Phys. Part A: Mol. \& Int. Phys., 158, 287-304.

Green, J. A., Butler, P. J., Woakes, A. J., Boyd, I. L. and Holder, R. L. (2003). Heart rate and rate of oxygen consumption of exercising macaroni penguins. J. Exp. Biol. 206, 3113-3113.

Groscolas, R., Decrock, F., Thil, M. A., Fayolle, C., Boissery, C. and Robin, J. P. (2000).

Refeeding signal in fasting-incubating king penguins: changes in behavior and egg temperature. Am. J. Physiol. Regul. Integr. Comp. Physiol. 279, R2104-12.

Guillemette, M., Richman, S. E., Portugal, S. J. and Butler, P. J. (2012). Behavioural compensation reduces energy expenditure during migration hyperphagia in a large bird. Funct. Ecol. 26, 876-883.

Halsey, L., Shepard, E. and Wilson, R. (2011). Assessing the development and application of the accelerometry technique for estimating energy expenditure. Comp. Biochem. and Phys. Part A: Mol. \& Int. Phys. 158, 305-314.

Halsey, L. G., Fahlman, A., Handrich, Y., Schmidt, A., Woakes, A. J. and Butler, P. J. (2007). How accurately can we estimate energetic costs in a marine top predator, the king penguin? Zoology 110, 81-92.

Halsey, L. G., Curran-Everett, D., Vowler, S. L. and Drummond, G. B. (2015). The fickle P value generates irreproducible results. Nature methods $\mathbf{1 2}, 179$.

Halsey, L. G., Jones, T. T., Jones, D. R., Liebsch, N. and Booth, D. T. (2011). Measuring energy expenditure in sub-adult and hatchling sea turtles via accelerometry. PLOS ONE 6, e22311.

Halsey, L. G., Portugal, S. J., Smith, J., Murn, C. P. and Wilson, R. P. (2009). Recording raptor behavior on the wing via accelerometry. J. Field Ornithol. 80, 171-177.

Halsey, L. G., Shepard, E. L., Hulston, C. J., Venables, M. C., White, C. R., Jeukendrup, A. E. and Wilson, R. P. (2008). Acceleration versus heart rate for estimating energy expenditure and speed during locomotion in animals: tests with an easy model species, Homo

This article is protected by copyright. All rights reserved. 
sapiens. Zoology 111, 231-241.

Halsey, L. G. and White, C. R. (2010). Measuring energetics and behaviour using accelerometry in cane toads Bufo marinus. PLOS ONE 5, e10170.

Halsey, L., Shepard, E., Quintana, F., Laich, A. G., Green, J. and Wilson, R. (2009). The relationship between oxygen consumption and body acceleration in a range of species. Comp. Biochem. and Phys. Part A: Mol. \& Int. Phys. 152, 197-202.

Halsey, L. G., Coward, S. R. and Thorpe, S. K. (2016). Bridging the gap: parkour athletes provide new insights into locomotion energetics of arboreal apes. Biol. Lett. 12, 10.1098/rsbl.2016.0608.

Hedrick, T. L., Usherwood, J. R. and Biewener, A. A. (2004). Wing inertia and whole-body acceleration: an analysis of instantaneous aerodynamic force production in cockatiels (Nymphicus hollandicus) flying across a range of speeds. J. Exp. Biol. 207, 1689-1702.

Hicks, O., Burthe, S., Daunt, F., Butler, A., Bishop, C. and Green, J. A. (2017). Validating accelerometry estimates of energy expenditure across behaviours using heart rate data in a freeliving seabird. J. Exp. Biol., jeb. 152710.

Lavine, M. (2014). Comment on murtaugh. Ecology 95, 642-645.

Liechti, F. and Bruderer, L. (2002). Wingbeat frequency of barn swallows and house martins: a comparison between free flight and wind tunnel experiments. J. Exp. Biol. 205, 2461-2467.

Lilienthal, O. (2001). Birdflight as the Basis of Aviation. translated from the second edition by AW Isenthal. Hummelstown.

Loftus, G. R. (1993). A picture is worth a thousand p values: On the irrelevance of hypothesis testing in the microcomputer age. Beh. Res. Meth., Instr., \& Comp. 25, 250-256.

Lyons, G., Halsey, L., Pope, E., Eddington, J. and Houghton, J. (2013). Energy expenditure during activity in the American lobster Homarus americanus: correlations with body acceleration. Comp. Biochem. and Phys. Part A: Mol. \& Int. Phys. 166, 278-284.

Nakagawa, S. and Schielzeth, H. (2013). A general and simple method for obtaining R2 from generalized linear mixed effects models. Meth. in Eco. and Evo. 4, 133-142.

Nudds, R. L. and Bryant, D. M. (2000). The energetic cost of short flights in birds. J. Exp.

This article is protected by copyright. All rights reserved. 
Biol. 203, 1561-1572.

Pennycuick, C. J. (2008). Modelling the flying bird. Elsevier.

Pennycuick, C., Fuller, M. and McAllister, L. (1989). Climbing performance of Harris' hawks (Parabuteo unicinctus) with added load: implications for muscle mechanics and for radiotracking. J. Exp. Biol. 142, 17-29.

Piersma, T. (2011). Why marathon migrants get away with high metabolic ceilings: towards an ecology of physiological restraint. J. Exp. Biol. 214, 295-302.

Qasem, L., Cardew, A., Wilson, A., Griffiths, I., Halsey, L., Shephard, E. L. C., Gleiss, A.

C. and Wilson, R. P. (2012). Tri-Axial Dynamic Acceleration as a Proxy for Animal Energy

Expenditure; Should We Be Summing Values or Calculating the Vector? PLOS ONE 7, e31187.

Rayner, J. (1994). Aerodynamic corrections for the flight of birds and bats in wind tunnels. J. of Zoo. 234, 537-563.

Rayner, J. M. (1999). Estimating power curves of flying vertebrates. . J. Exp. Biol. 202, 34493461.

Sakamoto, K. Q., Sato, K., Ishizuka, M., Watanuki, Y., Takahashi, A., Daunt, F. and

Wanless, S. (2009). Can ethograms be automatically generated using body acceleration data from free-ranging birds? PLOS ONE 4, e5379.

Sapir, N. and Dudley, R. (2012). Backward flight in hummingbirds employs unique kinematic adjustments and entails low metabolic cost. J. Exp. Biol. 215, 3603-3611.

Sapir, N., Wikelski, M., McCue, M., Pinshow, B. and Nathan, R. (2010). Flight modes in migrating European bee-eaters: heart rate may indicate low metabolic rate during soaring and gliding. PLOS ONE 5, e13956.

Schmidt-Nielsen, K. (1972). Locomotion: Energy cost of swimming, flying, and running. Science 177, 222-228.

Schwitzer, C. and Kaumanns, W. (2001). Body weights of ruffed lemurs (Varecia variegata) in European zoos with reference to the problem of obesity. Zoo Biology 20, 261-269.

Sellke, T., Bayarri, M. and Berger, J. O. (2001). Calibration of $\rho$ values for testing precise null hypotheses. The Am Stat. 55, 62-71.

This article is protected by copyright. All rights reserved. 
Shepard, E. L., Wilson, R. P., Halsey, L. G., Quintana, F., Laich, A. G., Gleiss, A. C.,

Liebsch, N., Myers, A. E. and Norman, B. (2008). Derivation of body motion via appropriate smoothing of acceleration data. Aq. Bio. 4, 235-241.

Spivey, R. J. and Bishop, C. M. (2013). Interpretation of body-mounted accelerometry in flying animals and estimation of biomechanical power. J. R. Soc. Interface 10, 20130404.

Taylor, L. A., Portugal, S. J. and Biro, D. (2017). Homing pigeons (Columba livia) modulate wingbeat characteristics as a function of route familiarity. J. Exp. Biol. 220, 2908-2915.

Team, R. C. (2013). R: A language and environment for statistical computing.

Usherwood, J. R., Stavrou, M., Lowe, J. C., Roskilly, K. and Wilson, A. M. (2011). Flying in a flock comes at a cost in pigeons. Nature $\mathbf{4 7 4 ,} 494$.

Ward, S., Bishop, C. M., Woakes, A. J. and Butler, P. J. (2002). Heart rate and the rate of oxygen consumption of flying and walking barnacle geese (Branta leucopsis) and bar-headed geese (Anser indicus). J. Exp. Biol. 205, 3347-3356.

Wasserstein, R. L. and Lazar, N. A. (2016). The ASA's statement on p-values: context, process, and purpose. The Am. Stat. 70, 129-133.

Weimerskirch, H., Bishop, C., Jeanniard-du-Dot, T., Prudor, A. and Sachs, G. (2016). Frigate birds track atmospheric conditions over months-long transoceanic flights.. Science 353, 74-78.

Welch, K. (2011). The power of feeder-mask respirometry as a method for examining hummingbird energetics. Comp. Biochem. and Phys. Part A: Mol. \& Int. Phys. 158, 276-286.

White, C. R., Cassey, P., Schimpf, N. G., Halsey, L. G., Green, J. A. and Portugal, S. J. (2013). Implantation reduces the negative effects of bio-logging devices on birds. J. Exp. Biol. 216, 537-542.

Wilson, R. P., White, C. R., Quintana, F., Halsey, L. G., Liebsch, N., Martin, G. R. and

Butler, P. J. (2006). Moving towards acceleration for estimates of activity specific metabolic rate in free living animals: the case of the cormorant. J. Anim. Ecol. 75, 1081-1090.

Zuur, A. F., Hilbe, J. M. and Ieno, E. N. (2013). A Beginner's Guide to GLM and GLMM with R: A Frequentist and Bayesian Perspective for Ecologists: Highland Statistics Limited.

This article is protected by copyright. All rights reserved. 


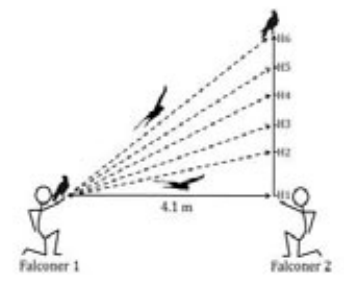

This article is protected by copyright. All rights reserved. 


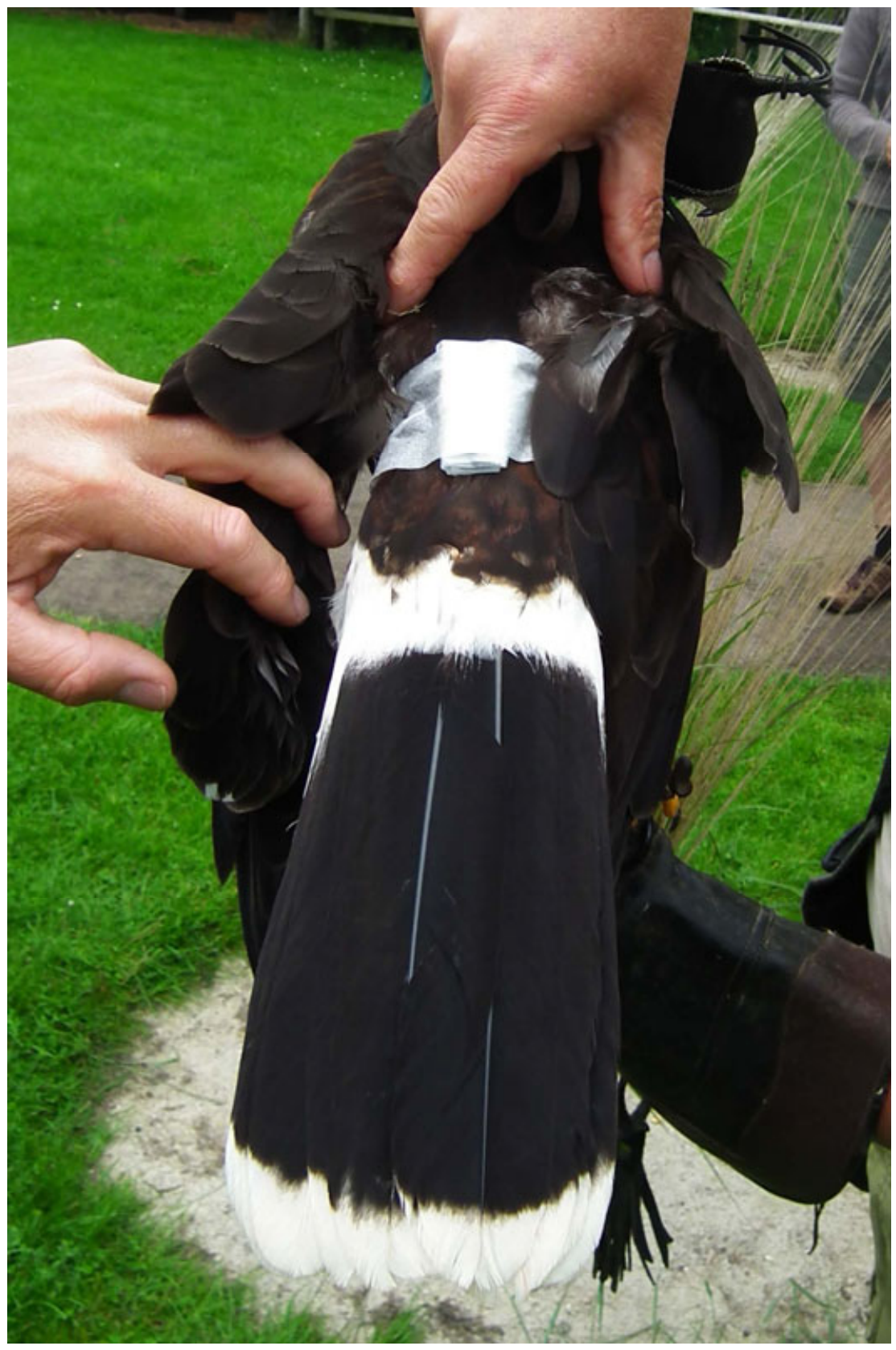

This article is protected by copyright. All rights reserved. 


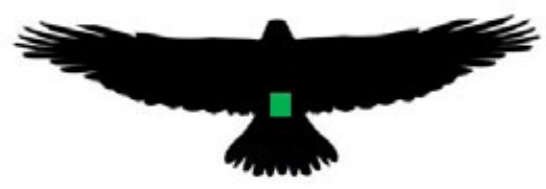

This article is protected by copyright. All rights reserved. 


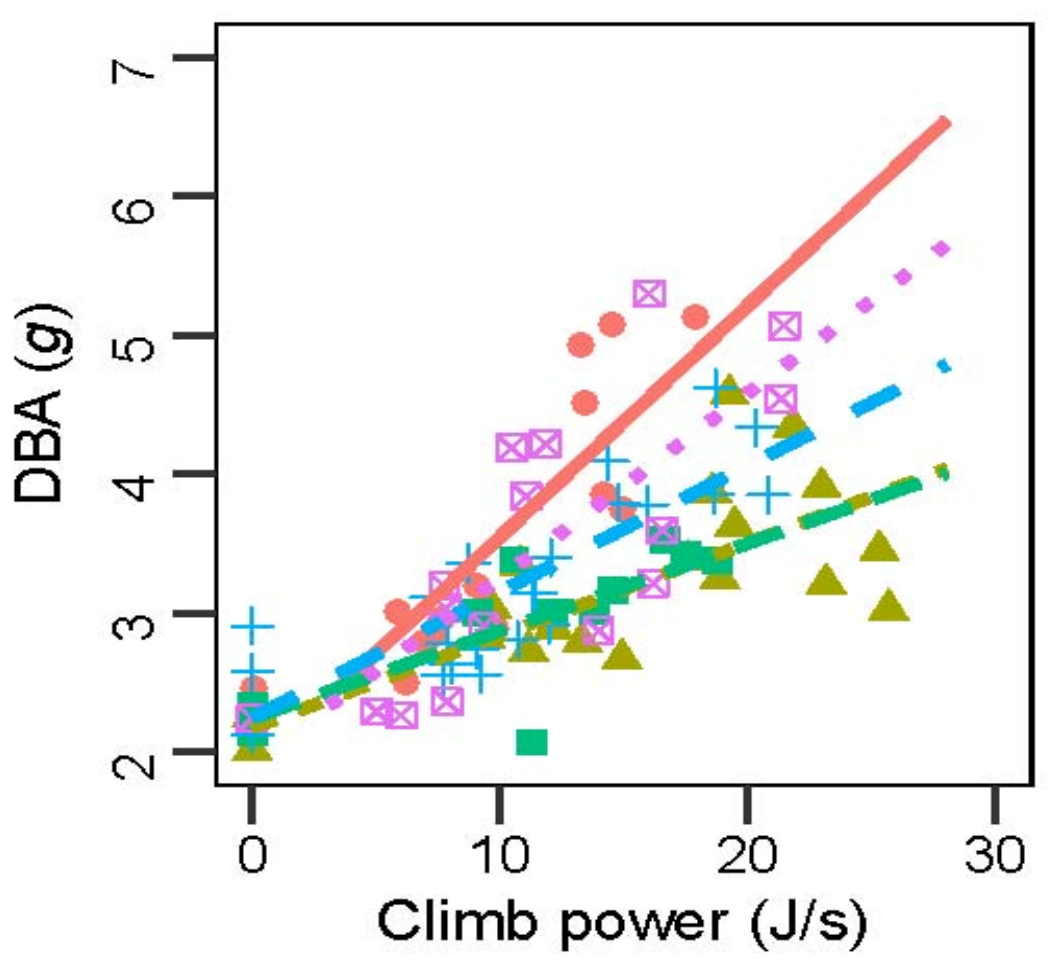

This article is protected by copyright. All rights reserved. 


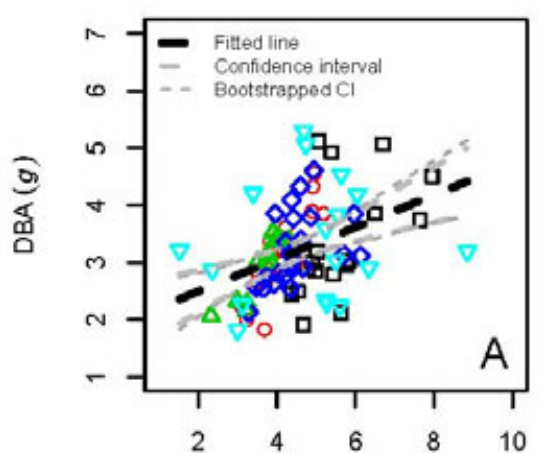

Body movement amplitude $(\mathrm{cm})$

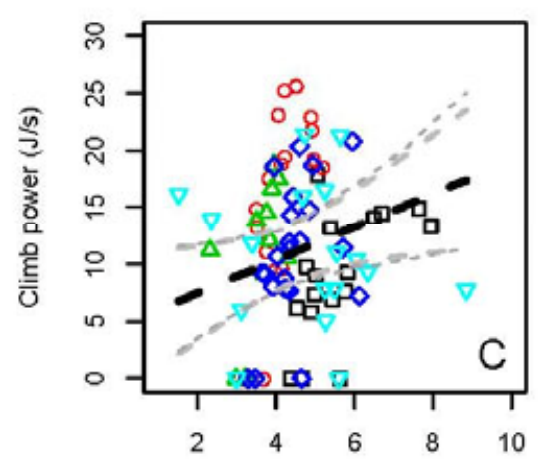

Body movement amplitude $(\mathrm{cm})$

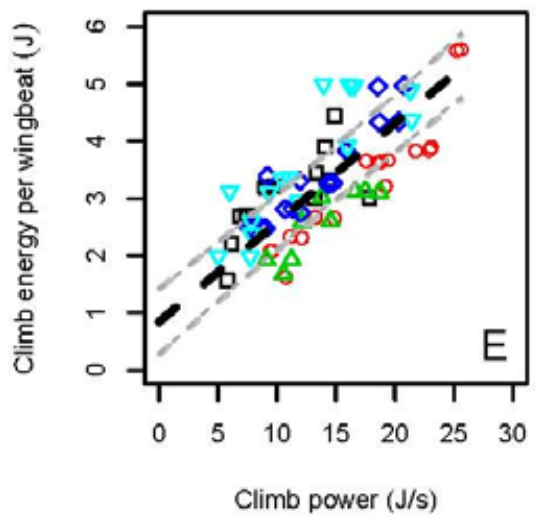

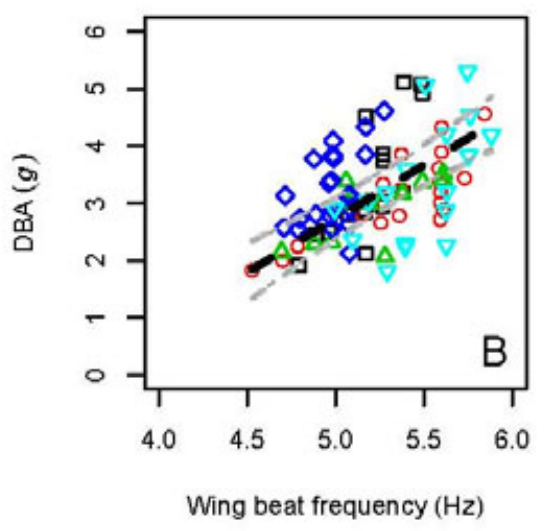
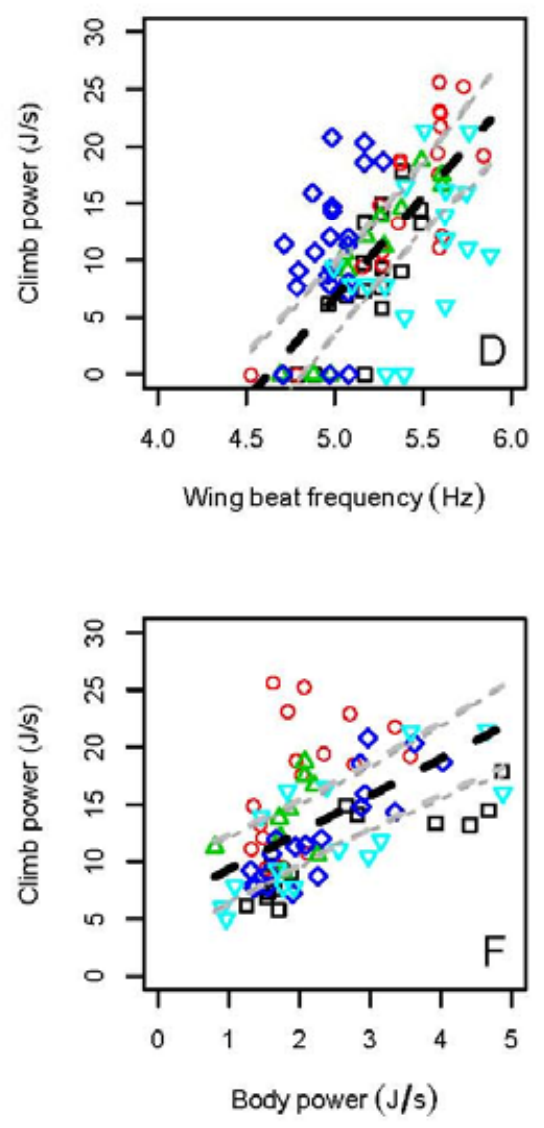

This article is protected by copyright. All rights reserved. 

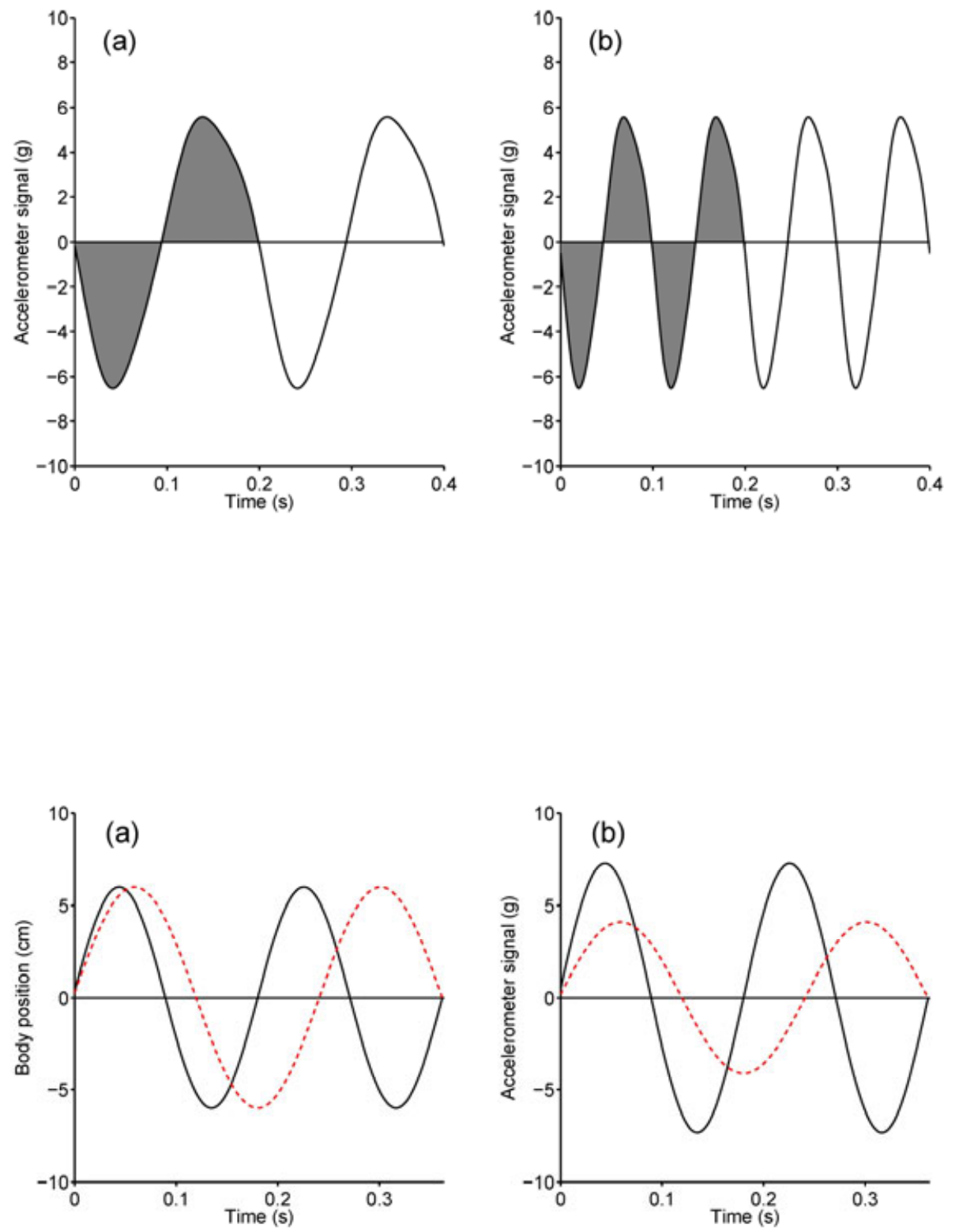

This article is protected by copyright. All rights reserved. 